Research paper

\title{
Why selection favors protandrous sex change for the parasitic isopod, Ichthyoxenus fushanensis (Isopoda: Cymothoidae)
}

\author{
MIN-LI TSAI ${ }^{1}$, JAN-JUNG $^{2} I^{2}$ and CHANG-FENG DAI ${ }^{1 *}$ \\ ${ }^{1}$ Institute of Oceanography, National Taiwan University, Taipei 106, Taiwan; ${ }^{2}$ National Museum \\ of Marine Biology and Aquarium, Che-Cheng, Pingtung, Taiwan \\ (*author for correspondence; fax: 886-2-23916693; e-mail: corallab@ccms.ntu.edu.tw)
}

Received 28 May 1999; accepted 2 February 2000

Co-ordinating editor: O. Leimar

\begin{abstract}
A flesh burrowing parasitic isopod, Ichthyoxenus fushanensis, was found infecting the body cavity of a freshwater fish, Varicorhinus bacbatulus, in pairs. The marked sexual size dimorphism, with much larger females than males, and the presence of penes vestige on mature females suggest a protandrous sex change in I. fushanensis. Here we investigate the question of why selection favors protandrous sex change for I. fushanensis, by analyzing the interactions among clutch size, female size, male size, and their host size. The number of manca, the first free-living juvenile stage released, per brood was closely related to the size of the female. Excluding the effects of interaction among causal variables, the negative correlation of male size alone on clutch size suggests that a small male did not limit an individual's mating and fertilization success. When the effect of host size is removed statistically, there exists a significant negative relationship between the sizes of paired males and females. This indicates that the resources available from host fish are limited, and that competition exists between paired male and female resulting in a trade-off of body size. Due to the very low success rate of hunting for a host of mancas, a female with larger body size and higher fecundity has a fitness advantage. To augment the clutch size, a productive combination is a smaller male and a larger female in a host. The constraints of the limited resources and the trade-off between the sizes of paired male and female may favor I. fushanensis to adopt the reproductive strategy of protandrous sex change resulting in a larger female and hence more mancas. The pattern of the interactions among male, female, and the number of mancas, may be considered as a selective force for I. fushanensis protandrous sex change, where the available resources are constrained by the size of the host.
\end{abstract}

Key words: Ichthyoxenus fushanensis, parasite, protandry, sequential hermaphroditism, sex change

\section{Introduction}

Both protandry and protogyny have possibly developed independently several times in the crustaceans, and the Isopoda is the only crustacean order in which both protandrous and protogynous species occur (Brook et al., 1994). In Isopoda, protandrous sex change occurs primarily within the parasitic 
suborders Epicarida (e.g. Family Bopyridae, Heminoniscidae and Cryptoniscidae) and Family Cymothoidae of Flabellifera (Brusca, 1981; Brook et al., 1994). Free-living species, based on a limited number of species examined, contain both protogynous and protandrous forms of sex change. Although a number of isopods have been reported to be protogynous or protandrous, little is known about the reproductive biology and life-history characteristics associated with the form of hermaphroditism in this group (Brook et al., 1994; Poulin, 1995a).

Ichthyoxenus fushanensis is a newly described parasitic isopod of Cymothoidae collected from the freshwater fish, Varicorhinus bacbatulus (Tsai and Dai, 1999). The isopod is found in a thin-walled membranous sac in the body cavity of the host, which is induced by I. fushanensis. The opening of the sac is an orifice near the posterior, ventral margin of the pectoral fin of the host fish. Usually a male and an upside-down female lie in the sac, with their posterior ends oriented toward the orifice. The orifice opens directly to the outer environment, and provides a channel for gas exchange, excretion and release of mancas. Ichthyoxenus fushanensis is a parasite specific to $V$. bacbatulus. Females lay the eggs into the brood pouch from April to July. Free-living mancas are released from June to October. The mancas without sex differentiation have a short free-living stage with good swimming ability. When the mancas are released, they hunt for the host immediately, and die within a week if they do not infect the host fish successfully (Tsai and Dai, 1999). Once they enter a host, they lose their swimming ability completely.

Ichthyoxenus fushanensis is usually found in pairs (male and female). Some are found as single males, but never as single females. When present in pairs, the female is always larger than the male. The marked sexual size dimorphism and the presence of penes vestige on mature females provide evidence of protandrous sex change in I. fushanensis (Tsai and Dai, 1999).

Sequential hermaphroditism is common in invertebrates and is often thought to be associated with brooding (Swell, 1994). The size-advantage model proposes that sequential hermaphroditism occurs when an individual reproduces most efficiently as a member of one sex when small or young, but as a member of the other sex when it gets older and larger (Brook et al., 1994). It predicts protogyny where there is sexual selection for larger males, and protandry where selection favors larger females with high fecundity. This model was originally proposed by Ghiselin (1969), and has since been extensively modeled (e.g., Warner, 1975; Leigh et al., 1976; Charnov, 1986; Iwasa, 1991). Protandry may be advantageous when female fecundity increase is dependent on age or size and male mating success remains independent of size (Warner, 1975, 1988; Brook et al., 1994). Conversely, protogyny may arise when small males are prevented from mating with females by larger males, making it 
advantageous to become male only when a competitive larger size is reached (Warner, 1988; Brook et al., 1994).

Here we provide an explanation for selective pressure favoring protandrous sex change for I. fushanensis based on the evolutionary trend of increasing clutch size for this parasitic isopod by examining the interrelationships among the female and male parasites and the host they infected. We focus on the interactions among the sizes of the host, the male and the female, how this may affect the number of offspring, and the association with the pattern of sex change.

\section{Material and methods}

The host fish, V. bacbatulus, which were infected by I. fushanensis, were collected from mountain streams at Wulai in northern Taiwan during summer 1998. The average altitude of our sampling sites is about $870 \mathrm{~m}$. A total of 93 individuals of host fish infected by I. fushanensis were collected. The fish infected by I. fushanensis were easy to distinguish from those uninfected by the existence of an orifice near the pectoral fin. All the host fish were brought back to the laboratory alive.

Each of the infected fish was cultured separately in a $35 \times 45 \mathrm{~cm}$ aquarium tank with filter and air supply system. Ichthyoxenus fushanensis in the hosts may contain embryos at different developmental stages and could not be examined from the exterior of host fish. To examine the clutch size in a standardized manca, host fish were dissected only when the first manca was released from the orifice, and I. fushanensis were removed from the parasitic sac. The body length of both hosts and parasitic isopods were measured in $\mathrm{mm}$. A water jet was used to remove the manca from the brood pouch of female, and the number of mancas was counted. Ultimately all hosts were dissected to determine the nature of parasite infection. The sexes of isopods were first examined by external anatomy. Sexually mature males can be distinguished from females mainly by having longer penes and an appendix masculina in endopodite of pleopod 2. In addition, there are some auxiliary morphological criteria for males, such as more oblong body shape and simpler maxilliped than that of females, scattered black dots over the whole body surface, and relatively slender uropods (Tsai and Dai, 1999). A few small individuals without significant exterior sexual characteristics were then dissected and internal reproductive organs were examined under a microscope.

Only the data from the fish containing paired parasites with brood were used for the correlation analyses. Partial correlation analyses were employed to reveal the relationships among the variables by excluding the influences from the other interrelated causal variables. Firstly, simple linear regressions were 
used to examine the dependency of parasite body size on host body size. The residuals which were unexplained by host size (the differences between observation values and predict values) in these linear models, were represented by relative values and used to detect the relation between male size and female size. The correlations between the clutch size and the female size, male size and host size were also revealed by a multiple regression to exclude the effects of the other two causal factors.

\section{Results}

The host and parasite body sizes

In general, female and male I. fushanensis exist in pairs in a host fish. Among the 93 host fish cultured, 54 individuals contain pairs of I. fushanensis with brood, 31 individuals contain pairs of isopods but without brood, and only 8 with unpaired individuals are found. Among the 8 unpaired individuals, 6 of them are male and 2 are too small (unmatured) to identify in sex. The body size of the host ranges from 70.8 to $127.0 \mathrm{~mm}$ in length. No V. bacbatulus larger than $140 \mathrm{~mm}$ are infected by I. fushanensis.

The mean $( \pm \mathrm{SE})$ body size of the brooding female isopod is $19.1 \pm 3.1 \mathrm{~mm}$, and ranges from 11.6 to $25.9 \mathrm{~mm}$. The mean size of male is $9.0 \pm 1.5 \mathrm{~mm}$, and ranges from 6.3 to $11.7 \mathrm{~mm}$. The body size of paired females is about 1.6 to 3.2 times that her mate. Mean body length differed significantly between paired females and males $(t=18.91, p<0.001)$. The size-frequency histograms of both paired females and males, with a fitting of normal distribution, show that there is little overlap in size range between them (Fig. 1). The distribution of unpaired individuals, however, is diffusive and overlaps both the paired male and female size ranges (Fig. 1). The smaller body size and more concentrated distribution of paired males than that of females indicates that the growth of the male is, however, constrained when his mate is present.

Both male size and female size are closely related to the size of host fish (Table 1). In addition, there is a positive relationship between the body sizes of paired males and females $(r=0.564, p<0.001)$. However, in such a situation, the real relationship between male and female sizes may be masked by the influence of a common factor, the host size. The partial correlation coefficients reveal the relationship between male and female sizes by eliminating the effects of host size (Table 1). When the effect of host size is removed, this relationship changes from positive to negative (Fig. 2). This negative relationship between the sizes of the male and female indicates that a larger female always accompanies a smaller male in a certain host. 


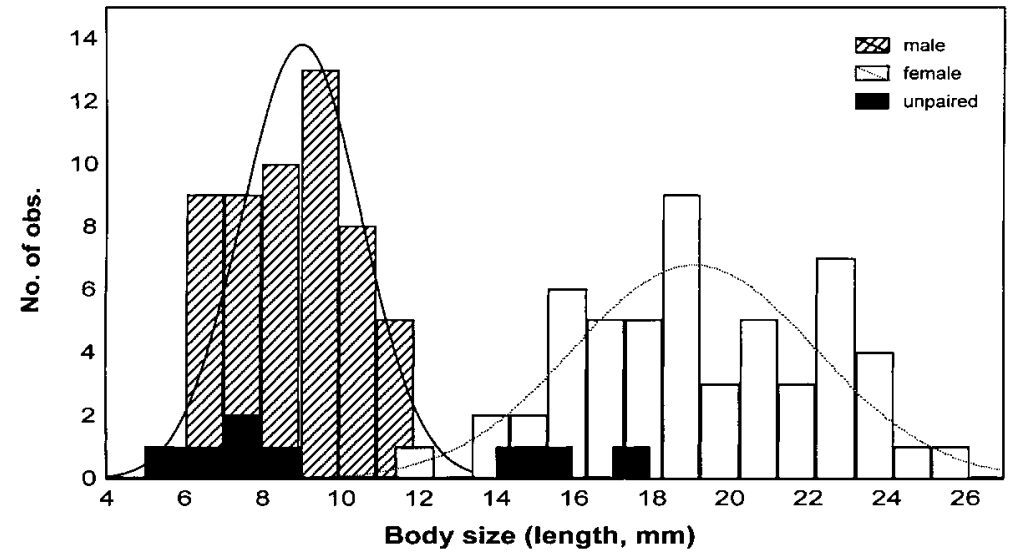

Figure 1. The size-frequency histogram of body length of paired males and females, and unpaired individuals of Ichthyoxenus fushanensis with a fit of normal distribution curve.

Table 1. The simple and partial correlation coefficients $(r)$ among the host size, female size, male size and the clutch size (number of manca per brood) of Ichthyoxenus fushanensis

\begin{tabular}{lccc}
\hline & Host size & Female size & Male size \\
\hline (a) Simple correlation coefficients & & & \\
Female size & $0.854^{\mathrm{a}}$ & & \\
Male size & $0.842^{\mathrm{a}}$ & $0.564^{\mathrm{a}}$ & \\
Clutch size & $0.823^{\mathrm{a}}$ & $0.984^{\mathrm{a}}$ & $0.498^{\mathrm{a}}$ \\
& $r$ (partial) & $t(d f)$ & $p$ \\
\cline { 2 - 4 } & & & \\
(b) Removal the effect of host size & -0.550 & $4.71(52)$ & $<0.001$ \\
Female size vs. Male size & & & \\
(c) Removal the effect of other two variables & +0.276 & $2.03(51)$ & $<0.05$ \\
Clutch size vs. Host size & +0.935 & $18.58(51)$ & $<0.001$ \\
Clutch size vs. Female size & -0.435 & $3.41(51)$ & $<0.01$ \\
Clutch size vs. Male size & &
\end{tabular}

${ }^{\text {a }}$ Significant at $p<0.001$.

The effects of host and parasite body size on clutch size

The mean clutch size is $485 \pm 201$, and ranges from 107 to 820 manca per brood. The clutch size is closely related to female size (Table 1). Besides, the significant simple correlation coefficients also show that the size of the host and the male isopods are positively related to clutch size (Table 1). But these positive correlations with clutch size may not be real, due to the existence of strong correlations among them. To examine the real effects of the sizes of the host, male and female on clutch size alone, the effects of the other two factors are removed through partial correlation analysis. For example, when we 


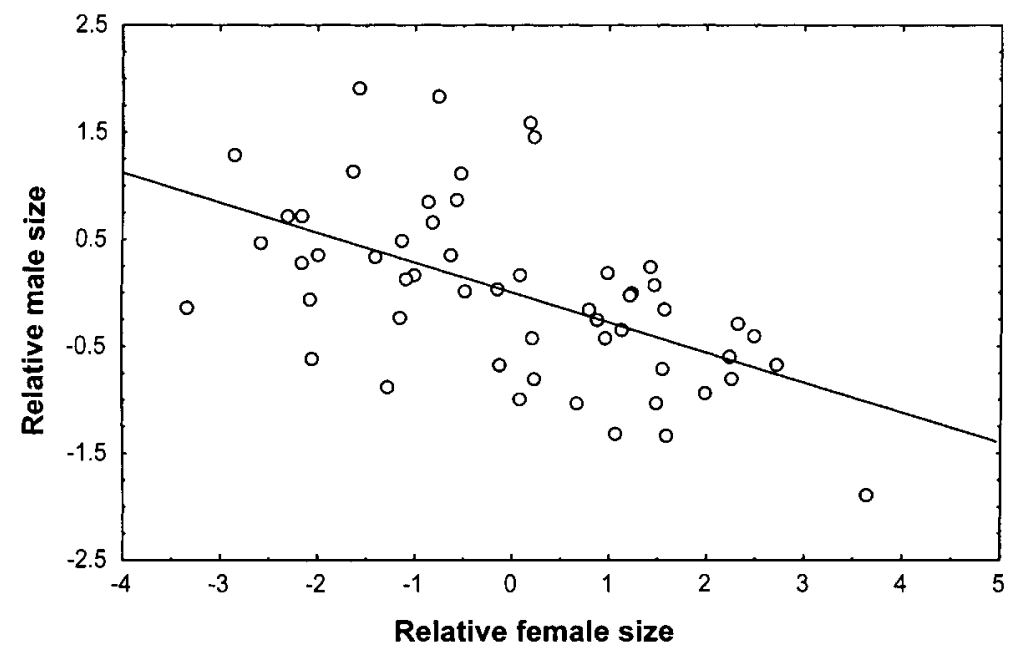

Figure 2. The relationship between the relative body size of paired male to female of Ichthyoxenus fushanensis, when removed the effects of their host size, respectively.

remove the effects of host size and male size, the number of manca is positively related to the female size alone $(r=0.935, p<0.001$; Fig. 3a). When the effects of the other two factors are removed through the same process, the clutch size is positively related to the host size $(r=0.276, p<0.05$; Fig. $3 b)$, but negatively related to male size $(r=0.435, p<0.01$; Fig. $3 \mathrm{c})$. These results indicate that the combination of larger host, larger female and smaller male may favor I. fushanensis to produce more offspring per brood.

\section{Discussion}

Protandrous sex change in Ichthyoxenus fushanensis

Ichthyoxenus fushanensis is a protandrous hermaphroditic isopod. The coexistence of oocytes and sperm in some specimens suggests that I. fushanensis is a hermaphroditic species (M.L. Tsai, personal observations). The sexual size dimorphism, with females much larger than males, the occurrence of unpaired males, and the presence of penes vestige on mature females provide evidence of protandrous sex change in I. fushanensis (Tsai and Dai, 1999). The protandrous sex change has been reported in other cymothoid isopods (Bowman, 1960; Williams and Williams, 1985).

The exact stimulus initiating the sex change in cymothoid isopods is still unknown. In I. fushanensis, the body size in itself cannot account for the timing of the sex change, because larger males do occur when it is alone. The 
(a)

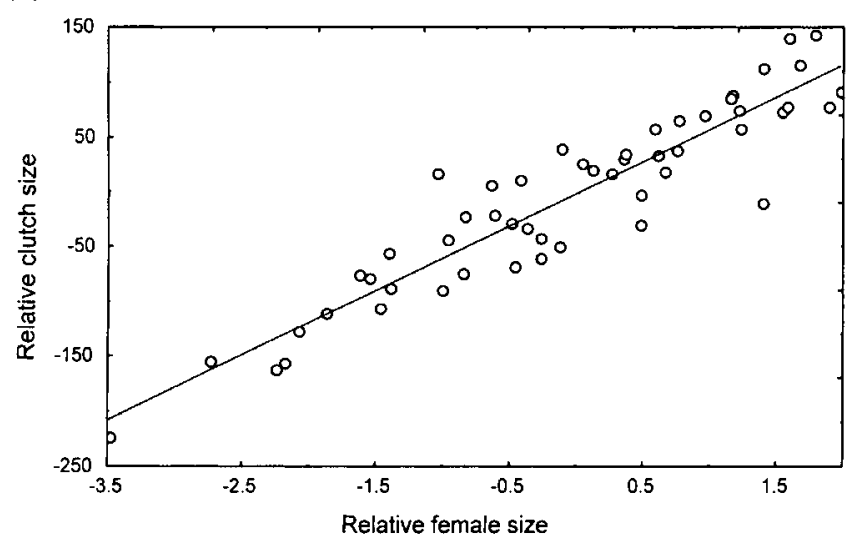

(b)

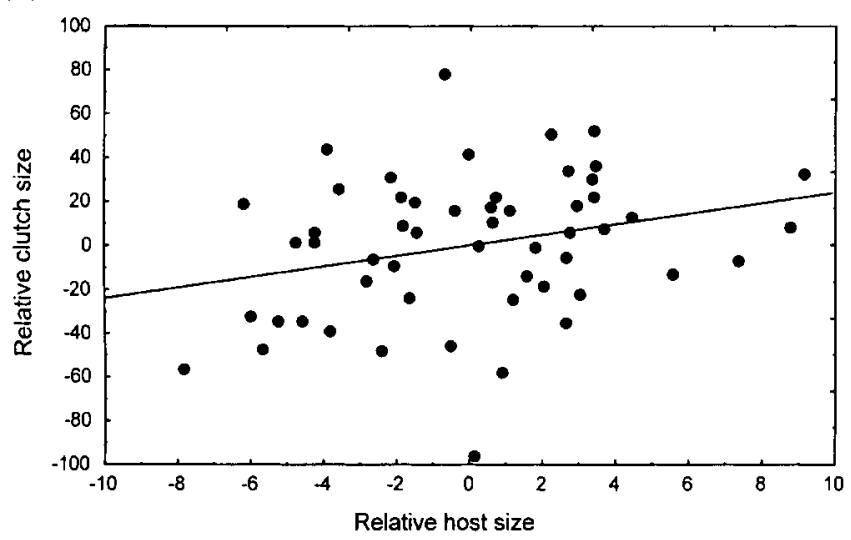

(c)

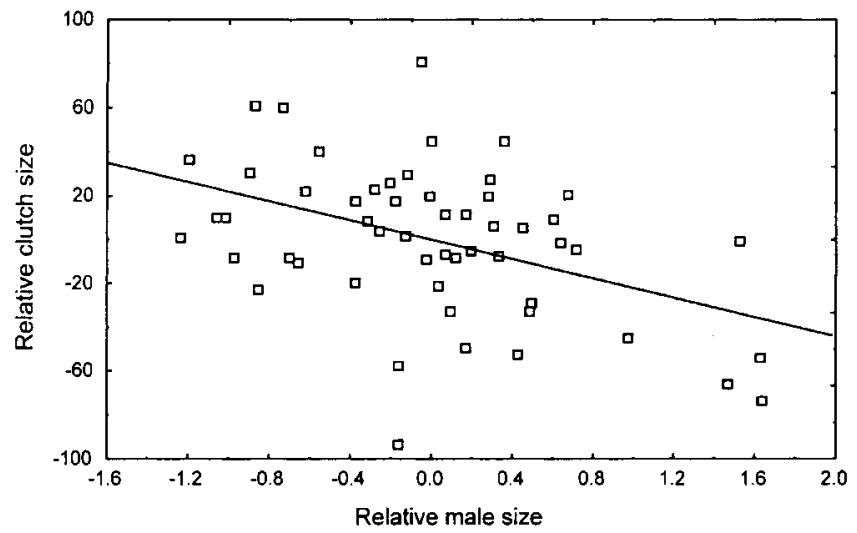

Figure 3. The relative clutch size of Ichthyoxenus fushanensis associate with the relative female, male and host size, respectively, when the effects of the other causal variables were removed. 
stimulus may be either the presence of a second individual entering the host or the absence of a resident female in the host fish when the manca first attached. The fact that the brooding females vary greatly in size (Fig. 1) may suggest that the first individual in the host grows with the male characteristics until a second individual enters the same host. The first individual may then, regardless of its size, undergo the sex change. Bowman (1960), and Williams and Williams (1985) also suggest that the sexual reversal from male to female of some cymothoid isopods may be induced by the entry of a second individual.

The effects of host and parasite body size on clutch size

Many factors may affect the clutch size of an isopod. Within many isopod species, fecundity (the number of eggs laid per brood) increases with female body size (e.g., Paris and Pitelka, 1962; Dearborn, 1967; Frankel, 1978; Wenner and Windsor, 1979; Shafir and Field, 1980; Brusca, 1981; Kittlein, 1991; Poulin, 1995a). In I. fushanensis, the clutch size increases with female size and the female size itself can explain about $94 \%$ of the clutch size variation (Table 1). The effect of male size on the clutch size is negative, when the effects of host and female size are removed. It seems likely that the smaller male did not limit an individual's mating and fertilization success. Besides, there is a significant negative relationship between the body sizes of paired males and females, after removing the host size effect. It also suggests that increasing male size may indirectly result in a reduction of clutch size by reducing the size of his mate.

Within some species of cymothoid isopods parasitic on fish, there is a positive relationship between the sizes of parasite and host (Brusca, 1981; Poulin, 1995a). The same phenomenon has been observed in several species of bopyrid isopods parasitic on crustaceans (e.g. Allen, 1966; Warren, 1974; Truesdale and Mermilliod, 1977; Wenner and Windsor, 1979). The measurement of clutch size comprises two components, i.e., fecundity (number of eggs per brood) of the female, and the brood mortality (mortality during the development from egg to manca). Since the duration of brooding for I. fushanensis is longer than 2 months (M.L. Tsai, personal observations), the host may affect not only the body sizes of the female and male, but also the clutch size. This positive effect of host size on clutch size is possibly due to increasing the available resources (may either be space or food or both) by the continuous growth of the host during brooding.

Why selection favors protandrous sex change?

The size-advantage model predicts protandry where selection favors larger females to produce more offspring. This model is apt to reveal the protandrous 
sex change in those species with high mortality of young, especially for those that have to hunt for a suitable environment in their young stage (Ghiselin, 1969; Charnov, 1986; Iwasa, 1991). In the laboratory, $99.6 \pm 0.4 \%$ of the manca of I. fushanensis failed to infect a host fish, and died within a week after being released (M.L. Tsai, unpublished data). Due to the constraints of very low success rate of hunting for a host, selective pressure may favor I. fushanensis to produce a larger female and hence carry more mancas. However, the protandrous sex change is not the obligatory reproductive strategy for animals to obtain larger and more productive females. Without the constraints of limited resources, there are many ways for animals to achieve it such as delayed maturity or higher female growth rate. The animals may also produce more and smaller eggs to compensate the juvenile mortality. Different reproductive strategies might be taken according to different styles of life. So, why is a protandrous sex change employed by I. fushanensis?

The observed negative relationship between female and male sizes suggests that a trade-off exists between the paired male and female. This body size trade-off may be caused by the limited resources of the host fish, and can be regarded as the result of competition between the paired male and female. Based on this trade-off between the sizes of the paired male and female, a smaller male is advantageous by achieving a larger and more productive female.

The constraint of low survival rate of mancas favors larger and more productive females. The competition between male and female for the limited resources may favor the combination of a smaller male and a larger female producing more mancas. Thus, due to the combined constraints of high juvenile mortality and the trade-off in female/male size, selection would favor a protandrous sex change for I. fushanensis.

\section{Parasitism and the patterns of sex change}

The widely accepted theory about parasites is that they are evolved toward smaller body size (Hanken and Wake, 1993) and extremely high fecundity (Price, 1974; Poulin, 1995b). Poulin (1995a) examines the evolutionary trends of body size and fecundity in free-living and parasitic isopods using comparative methods. He concludes that the body size of some parasitic isopod groups may have been inherited from free-living ancestors, and that parasitic isopods appear to have evolved toward higher fecundity despite not having evolved toward smaller body size after diverging from free-living ancestors. Many species in Order Isopoda are known to exhibit sex changes (Table 2). All the parasitic forms are protandrous, but free-living species are either protandrous or protogynous. This suggests that the protandrous sex change is an important determinant for the transition from free-living to parasitic life styles. The 
Table 2. Summary of the occurrence of protandrous and protogynous sex changes within Isopoda, which have been studied

\begin{tabular}{|c|c|c|c|}
\hline Taxa & Reference & Life-style & Sex change \\
\hline \multicolumn{4}{|l|}{ Order Isopoda } \\
\hline \multicolumn{4}{|l|}{ Suborder Anthuridea } \\
\hline \multicolumn{4}{|l|}{ Anthuridae } \\
\hline Cyanthura carinata & Legrand and Juchault, 1963 & $\mathrm{~F}$ & $\mathrm{G}$ \\
\hline C. polita & Burbanck and Burbanck, 1974 & $\mathrm{~F}$ & G \\
\hline C. profunda & Kensley, 1982 & $\mathrm{~F}$ & G \\
\hline \multicolumn{4}{|l|}{ Suborder Flabellifera } \\
\hline \multicolumn{4}{|l|}{ Sphaeromatidae } \\
\hline Paraleptosphaeroma glynni & Buss and Iverson, 1981 & $\mathrm{~F}$ & G \\
\hline Gnorimosphaeroma luteum & Brook et al., 1994 & $\mathrm{~F}$ & G \\
\hline G. oregonense & Brook et al., 1994 & $\mathrm{~F}$ & G \\
\hline G. naktongense & Abe and Fukuhara, 1996 & $\mathrm{~F}$ & G \\
\hline \multicolumn{4}{|l|}{ Cymothoidae } \\
\hline Emetha audouinii & Montalenti, 1941 & $\mathrm{P}$ & A \\
\hline Anilocra physodes & Montalenti, 1941 & $\mathrm{P}$ & A \\
\hline A. frontalis & Legrand and Juchault, 1970 & $\mathrm{P}$ & A \\
\hline Nerocila califronica & Brusca, 1978 & $\mathrm{P}$ & A \\
\hline Ichthyoxenus fushanensis & Tsai and Dai, 1999 & $\mathrm{P}$ & A \\
\hline Cuna insular & Williams and Williams, 1985 & $\mathrm{P}$ & A \\
\hline \multicolumn{4}{|l|}{ Suborder Epicaridea } \\
\hline \multicolumn{4}{|l|}{ Hemioniscidae } \\
\hline Hemioniscus balani & Kozloff, 1987 & $\mathrm{P}$ & A \\
\hline \multicolumn{4}{|l|}{ Liriopsidae } \\
\hline Liriopsis pygmaea & Kozloff, 1987 & $\mathrm{P}$ & A \\
\hline Cryptoniscidae & Charniaux-Cotton, 1960 & $\mathrm{P}$ & A \\
\hline \multicolumn{4}{|l|}{ Bopyridae } \\
\hline Munidion pleuroncodis & Markham, 1975 & $\mathrm{P}$ & A \\
\hline \multicolumn{4}{|l|}{ Suborder Oniscoidea } \\
\hline \multicolumn{4}{|l|}{ Oniscoidae } \\
\hline Rhyscotus ortonedae & Jackson, 1928 & $\mathrm{~F}$ & A \\
\hline R. parallelus & Jackson, 1928 & $\mathrm{~F}$ & A \\
\hline Philoscia elongata & Jackson, 1928 & $\mathrm{~F}$ & $\mathrm{~A}^{\mathrm{a}}$ \\
\hline
\end{tabular}

$\mathrm{P}$ - parasitic; $\mathrm{F}$ - free-living; $\mathrm{G}$ - protogynous; A - protandrous.

${ }^{\text {a }}$ Only found in local race of the species.

sequential hermaphroditism in isopods, especially for those free-living species, may be the adaptive strategies for various environments they occupied. They may be protandrous with a later maturity to produce more offspring, or may be protogynous with an earlier maturity of females to ensure reproduction. If the evolution trend toward high fecundity is important in the successful transition from a free-living to a parasitic life-style in isopods (Poulin, 1995a, b), we may then expect that natural selection would favor protandrous sex change resulting in a larger and more productive female. 


\section{Acknowledgements}

This study was supported by a grant from the National Science Council, ROC (NSC 89-2811-B-002-0042 to M.L. Tsai and NSC 89-2611-B002-001 to C.F. Dai). We would like to thank the Fu-shan Station, Taiwan Forestry Research Institute for logistic support of field works. We are grateful to Mr Ling-Chuan Zhuang for his help in collecting samples, and to Mr Richard Sleboda for his kindness in improving the manuscript. We would also like to thank the two anonymous reviewers for helpful comments on a previous draft of the manuscript.

\section{References}

Abe, M. and Fukuhara, H. (1996) Protogynous hermaphroditism in the brackish and freshwater isopod, Gnorimosphaeroma naktongense (Crustacea: Isopoda, Sphaeromatidae). Zool. Sci. 13, $325-329$.

Allen, J.A. (1966) Notes on the relationship of the bopyrid parasite Hemiathrus abdominalis (Krøyer) with its host. Crustaceana 10, 1-6.

Bowman, T.E. (1960) Description and notes on the biology of Lironeca puhi, n. sp. (Isopoda: Cymothoidae) parasite of the Hawaiian Moray Eel, Gymnothorax eurostus (Abbott). Crustaceana 1, 82-91.

Brook, H.J., Rawlings, T.A. and Davies, R.W. (1994) Protogynous sex change in the intertidal isopod Gnorimosphaeroma oregonense (Crustacea: Isopoda). Biol. Bull. 187, 99-111.

Brusca, R.C. (1978) Studies on the cymothoid fish symbionts of the eastern Pacific (Isopoda, Cymothoidae). I. Biology of Nerocila californica. Crustaceana 34, 141-154.

Brusca, R.C. (1981) A monograph on the Isopoda Cymothoidae (Crustacea) of the eastern Pacific. Zool. J. Linn. Soc. 73, 117-199.

Burbanck, M.P. and Burbanck, W.D. (1974) Sex reversal of female Cyanthura polita (Stimpson, 1855) (Isopoda, Anthuridae). Crustaceana 26, 110-112.

Buss, L.W. and Iverson, E.W. (1981) A new genus and species of Sphaeromatidae (Crustacea; Isopoda) with experiments and observations on its reproductive biology, interspecific interactions and color polymorphisms. Postilla 184, 1-3.

Charniaux-Cotton, H. (1960) Sex determination. In T.H. Waterman (ed.) The Physiology of Crustacea, vol. 1. Academic Press, New York, pp. 411-447.

Charnov, E.L. (1986) Size advantage may not always favor sex change. J. Theor. Biol. 119, 283-285.

Dearborn, J.H. (1967) Food and reproduction of Glyptonotus antarcticus (Crustacea; Isopoda) at McMurdo Sound, Antarctica. Trans. Roy. Soc. New Zealand 8, 163-168.

Frankel, B. (1978) The identification of gravid female of two subspecies of Trichonicus pasillus Brandt (Crustacea; Isopoda). J. Nat. Hist. 12, 177-183.

Ghiselin, M.T. (1969) The evolution of hermaphroditism among animals. Q. Rev. Biol. 44, 189-208.

Hanken, J. and Wake, D.B. (1993) Miniaturization of body size: organismal consequences and evolutionary significance. Annu. Rev. Ecol. Syst. 24, 501-519.

Iwasa, Y. (1991) Sex change evolution and cost of reproduction. Behav. Ecol. 2, 56-68.

Jackson, H.G. (1928) Hermaphroditism in Rhyscotus, a terrestrial isopod. Q. J. Microsc. Sci. 71, $527-539$.

Kabata, Z. (1981) Copepoda (Crustacea) parasitic on fishes: problems and perspectives. Adv. Parasit. 19, 1-17.

Kensley, B. (1982) Deep-water Atlantic Anthuridea (Crustacea: Isopoda). Smithson. Contrib. Zool. 346, 1-15. 
Kittlein, M.J. (1991) Population biology of Sphaeroma serratum Fabricius (Isopoda; Flabellifera) at the port of Mar del Plata, Argentina. J. Nat. Hist. 25, 1449-1459.

Kozloff, E.N. (1987) Marine Invertebrates of the Pacific Northwest. University of Washington Press, Seattle, Washington.

Legrand, J.J. and Juchault, P. (1963) Mise en évidence d'un hermsaphrodisme protogynique fonctionnel chez 1'Isopode Anthuride Cyanthura carinata (Kroyer) et étude du mecanisme de l'inversion sexuelle. C. R. Acad. Sci. Paris 256, 2931-2933.

Legrand, J.J. and Juchault, P. (1970) Controle de la sexualité chez les crustacés isopodes gonochoriques et hermaphrodites. Bull. Soc. Zool. Fr. 95, 551-563.

Leigh, E.G., Charnov, E.L. and Warner, R.R. (1976) Sex ratio, sex change, and natural selection. Proc. Natl. Acad. Sci. USA 73, 3656-3660.

Lowry, J.K. and Stoddart, H.E. (1986) Protandrous hermaphrodites among the Lysianassoid Amphipoda. J. Crust. Biol. 6(4), 742-748.

Markham, J.C. (1975) Biological results of the University of Miami deep sea expeditions. Part 113. A review of the bopyrid isopod genus Munidion, parasitic on galatheid crabs in the Atlantic and Pacific. Bull. Mar. Sci. 25, 422-441.

Montalenti, G. (1941) Studi sull' ermafroditismo dei cimotoidi - I. Emetha audouinii (M. Edw.) e Anilocra physodes (L.). Pubbl. Stn. Zool. Napoli. 18, 337-394.

Paris, O.H. and Pitelka, F.A. (1962) Population characteristics of the terrestrial isopod Armadillidium vulgare in California grassland. Ecology 43, 229-248.

Poulin, R. (1995a) Evolutionary influences on body size in free-living and parasitic isopods. Biol. J. Linn. Soc. 54, 231-244.

Poulin, R. (1995b) Evolution of parasite life-history traits: myths and reality. Parasitol. Today 11, 342-345.

Price, P.W. (1974) Strategies for egg production. Evolution 28, 76-84.

Shafir, A. and Field, J.G. (1980) Population dynamics of the isopod Cirolana imposita Barnard in the kelp-bed. Crustaceana 39, 185-196.

Sibly, R.M. and Calow, P. (1986) Physiological Ecology of Animals: An Evolutionary Approach. Blackwell, Oxford.

Swell, M.A. (1994) Small size, brooding, and protandry in the Apoidid sea cucumber Leptosynapta clarki. Biol. Bull. 187, 112-123.

Truesdale, F.M. and Mermilliod, W.J. (1977) Some observation on the host-parasite relationship of Macrobrachium ohione (Smith) (Decapoda, Palaemonidae) and Probopyrus bithynis Richardson (Isopoda, Bopyridae). Crustaceana 32, 216-220.

Tsai, M.L. and Dai, C.F. (1999) Ichthyoxenus fushanensis, new species (Isopoda: Cymothoidae) parasite of the freshwater fish, Varicorhinus bacbatulus, from northern Taiwan. J. Crust. Biol. 19, 917-923.

Warner, R.R. (1975) The adaptive significance of sequential hermaphroditism in animals. Am. Nat. 109, 61-82.

Warner, R.R. (1988) Sex change and the size-advantage model. Trends Ecol. Evol. 3, 133-136.

Warren, P.J. (1974) Some observations on the relationship of the bopyrid parasite Hemiarthrus abdomonalis (Krfyer) with Pandalus montagui Leach and Pandalus borealis Krfyer. Crustaceana 27, 21-26.

Wenner, E.L. and Windsor, N.T. (1979) Parasitism of galatheid crustaceans from the Norfolk Canyon and Middle Atlantic Bight by bopyrid isopods. Crustaceana 37, 293-303.

Williams E.H. Jr. and Williams, L.B. (1985) Cuna insularis new genus and new species isopoda Cymothoidae from the gill chamber of the sergeant major Abudefduf saxatilis osteichthyes in the West Indies. J. Parasit. 71, 209-214. 